M. Noble, admitted that if Scotland were to overtake the United Kingdom average then its rate of growth would have to exceed 4 per cent, but there was no other indication that the Government's plan might accept the figure suggested in the Political and Economic Planning Broadsheet. Mr. J. Boyd-Carpenter, the Chief Secretary to the Treasury, stressed the significance of university developments, particularly at the University of Strathelyde. In winding up for the Government, Sir Keith Joseph, whilo admitting the need for some machinery at regional level, maintained that this should be achieved by strengthening central Govenment in the regions and not by instituting a new tir $r$ of regionally elected authorities. $\mathrm{He}$ also stressed the great influence of central Government as a customer for Government supplies and its opportunities for creating by fiscal and economic policies a climate of opinion which encouraged private enterprise to expand. In co-operation with private and public enterprise it could also help to ensure that unit costs enable private enterprise to remain competitive.

\title{
UNESCO EXPEDITION TO THE LIMESTONE AREAS OF THAILAND
}

$\mathrm{U}$ NDER the sponsorship of the Unesco Science Cooperation Office in Djakarta, the fourth Uneseo training expedition was held in Thailand during 1963 .

The expedition formed a continuation of the research work on the flora of limestone areas in tropical south-east Asia, made by three former Unesco expeditions, namely, Java (1960), Borneo (Sarawak, 1961), and Malaya (Ulu Kelantan, 1962) (see Nature, 196, 1169; 1962). Two preliminary excursions were made to the north and northeast of Thailand by Mr. T. Smitinand of the Thai Forest Department (leader) anr? Dr. H. Sleumer of the Rijksherbarium, Leyden (instructor), together with several young Thai forest officers. The first was to the Doi Chiengdao, which, at $2,180 \mathrm{~m}$, is the highest limestone massive of Thailand. The flora of this area, at least as far as the upper, more open vegetation, has so far been fairly well collected; however, as yet, it has not been worked out critically. The second excursion was to the Pha Nok Khao south of Loie, which is a very steep limestone hill, c. $900 \mathrm{~m}$, the flora of which was collected for the first time.

The training expedition proper was held during September 17-October 8. The participants came from Malaya (University of Kuala Lumpur), Singapore (Botanic Garden), the Philippines (Los Baños), Java (Bogor Botanie Garden and Herbarium), South Vietnam (Saigon) and Thailand. The party, consisting of 14 members, first went to Surathani in the south of the Thai Peninsula and from there to a camp set up by the local Forestry Department, situated $44 \mathrm{~km}$ on the road from Surathani to Takuapa in the region of numerous limestone hills. During the expedition, seven of these hills were climbed: Khao Phra Rahu, Khao Lek, Khao Wong, Khao Na Dang, Khao Pak Chawng, Khao Lang Tao and Khao Dai Kuad, ranging in altitude from 180 to about $500 \mathrm{~m}$; each proved to have a few species which were not found on the others, though in general the flora, especially on the lower slopes, was the game.
On September 28 the camp was left and a visit paid to Ko Prap, an island off Surathani. On September 29 the party returned to Bangkok, and on October 1 started from there on the second part of the expedition to Muak Lek, a forestry experimental station to the north of Saraburi, about $130 \mathrm{~km}$ north of Bangkok. From this base the limestone hills Muak Lek, Tap Kwang and Khao Sawng Phi Nawng were climbed; these varied in altitude from 350 to $400 \mathrm{~m}$. The herbarium collections made on limestone hills amounted to a total of 400 specimens, each, so far as was possible, with 5 duplicates (this material will be distributed to the Herbaria of Bangkok (Forest Department), Singapore, Kew, Leyden and Bogor for further investigation). Besides these, living material of about 150 species, especially orchids, was collected to be eultivated and observed in various botanic gardens. In general, it can be said that the vegetation on the limestone hills in the Thai Peninsula near Surathani is remarkably different from that in Ulu Kelantan, Malaya, and is relatively drier. As to the limestone flora in Thailand-where the limestone outerops are found extending from the very south up to the border with Burma in the north in a broken chain over a distance of about $1,600 \mathrm{~km}$-it must be said that the botanical collections made so far are too scarce to give any indication of the areas and routes of migration of the species of this peculiar flora. It is for this reason that the next Unesco Training Expedition will probably be held in Thailand once more, and hence stimulate further research on limestone there. The flora on many of these ancient (mostly Permian) limestone hills is suffering from human inter. ference; this raises an additional urgency for such botanical investigations, which, up until now, have been too fow and far between. A better understanding would also make available the information necessary to present well-founded scientific advice to the Thai Government to consider some of these hills suitable for declaration as nature reserves.
H. SLEUMER

\section{THE ROYAL SOCIETY OF ARTS}

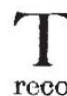
HE tremendous increase in candidates taking tho various examinations of the Royal Society of Arts is recorded in the November issue of its Journal (111, No. 5088; November 1963). Twelve years ago the number of subject-entries in one year was about 130,000 . To-day it is 700,000 and, at the present rate of growth, will excced one million in two or three years' time. Although entries are mainly from candidates at centres in Great Britain and Northern Ireland, there was an increased demand from overseas centres where the numbers went up from 40,271 in 1962 to 53,543 in 1963 . Nigeria is by far the largest of the overseas centres in regard to number of candidates, but the examinations were also in good demand at other centres in West Africa (Gambia, Ghana,
Sierra Leone and West Cameroons). A fuller appreciation of the widespread demand for the Society's examinations can be obtained from the following list of overseas centres in 1963: Aden, Bahamas, Bermuda, British Guiana. British Honduras, Brunei, Cyprus, Ethiopia, Falkland Islands, Fiji, Gibraltar, Jamaica, Kenya, Malta, Mauritius. Nyasaland, Sabah (lately North Borneo). St. Helena, St. Lucia, Southern Rhodesia, Tanganyika, Trinidad, and the British Virgin Islands. In addition. there were a fow centres in foreign countries, mainly for the examinations in English, under the control of officials of the British Embassy or of the British Council.

Particularly pleasing was the increase in demand for the examinations for the Ordinary National Cortificate in 
Business Studies, which is organized by the Society in collaboration with the London Chamber of Commerce. There were 152 candidates for the first-year examinations, and 64 for the second; the number of colleges presenting candidates increased from 12 to 18 .

For the parallel scheme for the award of the Ordinary Certificate in Business Studies to candidates at centres outside the British Isles, which is administered by the London Chamber of Commerce on behalf of the two bodies, entries for the first-year examinations were received from 11 candidates at a college in Nigeria. There is every indication that there will be an increasing demand for this scheme from colleges in various parts of the world.

Details are also given of progress with the Certificate in Office Studies. In March 1963 the Minister of Educa- tion decided to introduce a new national award, the "Certificate in Office Studies", for young office workers who wish to pursue courses of further education but do not possess the educational qualifications required for entry to a course leading to the Ordinary Nati onal Certificate in Business Studies. It is hoped that employers will encourage their young office workers to take the twoyear course of study by granting them day or block release. The Society, together with other examining bodies approved for the purpose, will organize examinations for the Certificate, the administration of which is in the hands of a National Committee comprising representatives of the Ministry of Education, of associations of teachers, employers and Trade Unions, and of national and regional examining bodies. The examinations will be offered for the first time in June 1965 .

\title{
ATYPICAL MYCOBACTERIA
}

A MONG the many items of interest in the eighteenth annual report of the Queensland Institute of Medical Research* is one describing various investigations of atypical mycobacteria. Points of special interest recorded include the value of bone-marrow culture in the diagnosis of human infection with atypical mycobacteria, the isolation of $M$. ulcerans from a chronic ulcer and of what appears to be $M$. balnei from a water tank, the profusion of mycobacteria of many types in water and wet environments, and the possible use of thiosemicarbazone in classification.

The culturing of bone-marrow specimens obtained by needle biopsy has proved a valuable means of investiga. tion. The finding of atypical mycobacteria in the sputum may be of doubtful clinical significance, as these organisms may be present as commensals on the surface of lesions caused by other processes such as bronchiectasis and congenital abnormalities. On the other hand, their presence in the bone marrow is clear evidence of invasion.

A portion of each specimen was cultured without pretreatment, and another after treatment with sodium hydroxide. All tubes were incubated for six months, and primary growth was observed in some cases only after four months' incubation. Bone-marrow cultures were made and held for six months from 31 patients, most of whom had acid-fast bacilli in the sputum. Thirteen, or 42 per cent, were positive. Of the sixteen strains isolated from the thirteen specimens, eight belonged to group 4 and five to group 5; three are not yet typed. An attempt will be made to assess the significance of both positive

- Eighteenth Annual Report of the Council of the Queensland Institute of Medical Research for the year ended 30th June, 1963. Pp. 16. (Brisbane: The Council of the Qneensland Institute of Mcdical Research, 1963.) and negative findings against repeated clinical examinations by a chest physician.

A strain isolated from a skin ulcer was identified as $M$. ulcerans by the foot-pad inoculation method. The patient was a timber-getter who developed a scaly lesion on the forearm which later progressed to an ulcer with undermined edges. Numerous acid-fast bacilli were seen in the pus. Cultures made after treatment with sodium hydroxide were incubated at $30^{\circ}$ and $37^{\circ} \mathrm{C}$. No growth appeared at $37^{\circ} \mathrm{C}$ but, after four months, some growth was seen at $30^{\circ} \mathrm{C}$. On sub-culture, the mustard-coloured colonies grew in four weeks.

Mycobacteria occur in great numbers in water, mud and beach sand. During 1962, swimming pools, rain-water tanks and city water supplies were examined. Specimens of open water and swabs from the walls of swimming pools and reservoirs were used.

The types of mycobacteria which were isolated from water were similar to those found previously in dust, animal glands and tonsils, and they occurred in similar proportions. The number of organisms in the moist habitats is much larger than in dusts.

One organism which conformed with the cultural and serological characters of $M$. balnei was isolated from a rain-water tank. Epidemics caused by $M$. balnei were reported among bathers elsewhere, but it has not yet been isolated from local swimming pools.

$M$. balnei shows a characteristic type of pathogenicity when injected into the foot-pad of mice, and other strains of atypical acid-fast organisms show a similar predilection for the foot-pad. This method is being applied to the further characterization of strains in the Institute's collection.

\section{SIMULTANEOUS MEASUREMENTS AND SPECTRAL ANALYSIS OF MICROPULSATION ACTIVITY}

\author{
By R. L. KOMACK and A. S. ORANGE
}

U.S. Air Force Cambridge Research Laboratories

\author{
F. X. BOSTICK, JUN. \\ University of Texas
}

\author{
AND \\ Dr. T. CANTWELL \\ Geoscience Inc., Cambridge, Mass.
}

D URING the autumn of 1962 a series of simultaneous measurements of telluric current micropulsation activity were made in Texas, Puerto Rico and Trinidad. The frequency range covered was from 0.01 to $0.25 \mathrm{c} / \mathrm{s}$.
This article presents the initial results of spectral analysis and investigations of dependence on latitude.

For this series of measurements, spectral analysis reveals a peak occurring around periods of $20-30 \mathrm{sec}$. 